\section{Current opinion on treatment of asymptomatic retinal detachments}

N Ahmad and J West

Keywords: asymptomatic; treatment; retinal detachment; current opinion; survey

\begin{abstract}
Aims To determine the current opinion of vitreoretinal consultants in the UK on the treatment of asymptomatic retinal detachments.
\end{abstract}

Methods A questionnaire survey of UK and Eire vitreoretinal consultants on recommended therapy for eight different case scenarios of asymptomatic retinal detachment.

Results A questionnaire was sent to $\mathbf{1 1 5}$ consultants in UK and Eire. Fifty-four per cent were returned. The majority of surgeons favoured active intervention for most types of asymptomatic retinal detachment, with surgery being the most popular. Laser demarcation of the detached retina was the second most favoured approach followed by observation alone. Discharge with advice to seek attention if symptoms appeared was the least frequently recommended. Recommended management varied considerably for each scenario. The presence or absence of a demarcation line had the greatest influence on the management of each case. Age of patient had a much smaller effect, and degree of myopia had very little effect.

Conclusions Surgery remains the most common recommended management for an asymptomatic retinal detachment. The striking outcome of the survey is the variability in responses for any given scenario, ranging from surgical intervention to the patient being discharged with advice. This reflects the absence of hard clinical evidence to support any particular management option in such cases. As patient involvement in decision making over management is essential, the opinions expressed in this survey may not be a true reflection of actual practice, although it does highlight the need for further research in this field to provide guidance for treatment of this important condition.

Eye (2007) 21, 1179-1185; doi:10.1038/sj.eye.6702432; published online 19 May 2006

\section{(}

\section{Introduction}

As opposed to symptomatic retinal detachment, the need to treat asymptomatic retinal detachment is not as well defined. It is much rarer than symptomatic retinal detachment, but like symptomatic detachment can vary in size, cause, age of presentation, presence or absence of a demarcation line, and the refractive status of the patient. These patients are often young with excellent vision in the affected eye, often better than 6/6, and in such cases, we have to consider intervention that has an associated morbidity for an asymptomatic condition. A review of the literature seems to suggest arguments both for and against active treatment. Because of the differing opinion expressed in the literature on the treatment of asymptomatic retinal detachment, we were interested to know the current opinion on management of such cases by vitreoretinal consultants in the UK and Ireland.

\section{Materials and methods}

A questionnaire with a covering letter was sent to all consultant BEAVRS members in the UK and Ireland. The scenario was of an asymptomatic patient referred by the optician. The respondents were asked to indicate the management option they would recommend to the patient for eight different clinical retinal findings. Each case scenario also varied in terms of patients' age, presence of a demarcation line, and degree of myopia. There was no option to let the patient decide. All cases were assumed not to have a family history of retinal detachment.
Ophthalmology

Department, Royal

Hallamshire Hospital, Sheffield, UK

Correspondence: N Ahmad, Ophthalmology

Department, A Floor Royal Hallamshire Hospital, Glossop Road, Sheffield S10 2JF, UK Tel: + 44 (0) 1142711900 ext 68863;

Fax: $+44(0) 1142713682$

E-mail: ophthdoc@tesco.net

Received: 30 October 2005 Accepted in revised form: 20 April 2006

Published online: 19 May 2006

Presented at the BEAVRS meeting 2003 


\section{Results}

Of 115 questionnaires sent out, 64 (54\%) were returned. Individual case scenarios are presented below, along with tables providing the results from the survey. Because the presence or absence of a demarcation line was found to have the greatest influence on management recommended, the effect of this is shown for each clinical scenario. The last column marked 'Other' represents the respondents giving a choice of more than one. All figures in the tables are in percentages.

\section{Scenario 1: inferior dialysis}

The majority recommended surgery, with the absence of a demarcation line making the likelihood of intervention more probable. Nine per cent recommended laser barrage, with only a minority opting for discharge without follow-up (Figure 1, Table 1).

\section{Scenario 2: inferior dialysis with old demarcation line}

The extension of detachment beyond an old demarcation line caused a higher number to choose surgery as a first option, probably because this may represent a recent worsening of a chronic condition. The presence of a second new demarcation line meant that more people would be willing to observe as compared to no new demarcation line (Figure 2, Table 2).

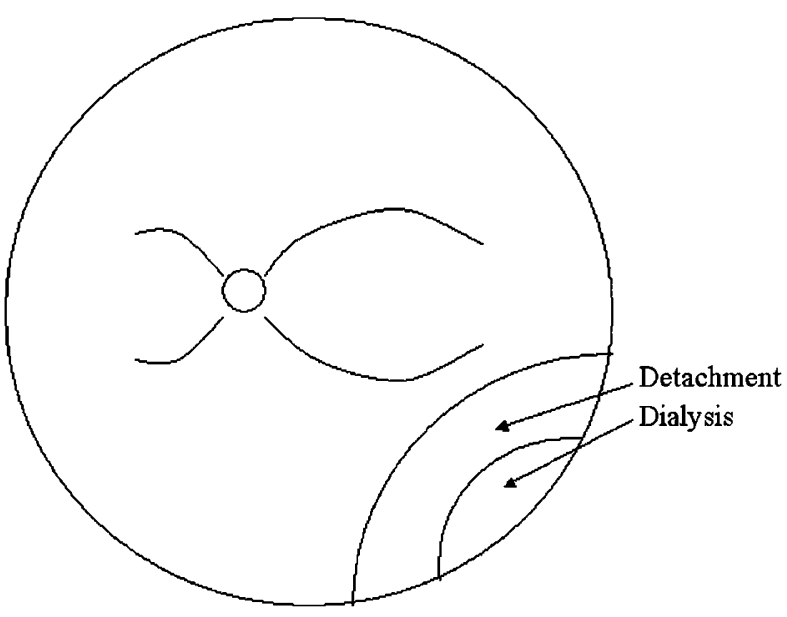

Figure 1 Inferior dialysis without old demarcation line.

\section{Scenario 3: superior round hole retinal detachment}

This scenario showed the presence of a considerable amount of subretinal fluid around a superior round hole. The opinion on management in this case was much more varied. If a demarcation line was present, $29 \%$ opted to discharge with advice to seek attention if symptomatic. Without the demarcation line, 60\% would treat this kind of break with barricade laser. Observation was the least popular choice overall, and surgery was generally not recommended in this scenario (Figure 3, Table 3).

\section{Scenario 4: inferior round hole retinal detachment 1}

Again, the presence of a demarcation line reduced the proportion advocating active treatment (from 78 to $51 \%$ ). Most respondents opted for surgery, followed by observation, laser, and discharge with advice (Figure 4, Table 4).

\section{Scenario 5: inferior round hole retinal detachment 2}

The larger area of detachment increased the percentage opting for surgery with the absence of a demarcation line

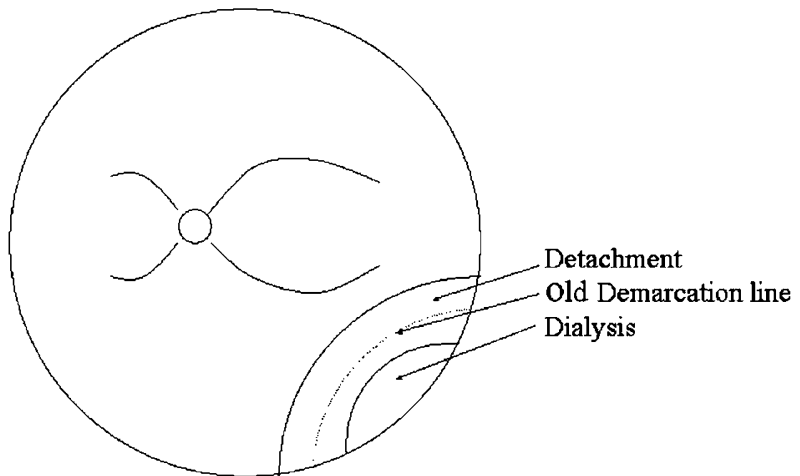

Figure 2 Inferior dialysis with old demarcation line.

Table 2 Inferior dialysis with old demarcation line

\begin{tabular}{lccc}
\hline \% Choosing surgery & Total & $\begin{array}{c}\text { New } \\
\text { demarcation }\end{array}$ & $\begin{array}{c}\text { No new } \\
\text { demarcation }\end{array}$ \\
\hline No old demarcation & 73 & 61 & 86 \\
Old demarcation & 83 & 77 & 90 \\
\hline
\end{tabular}

Table 1 Inferior dialysis without old demarcation line

\begin{tabular}{|c|c|c|c|c|c|c|c|}
\hline$\%$ & Discharge & Observe indefinite & Observe 2 months & Observe 6 months & Laser & Surgery & Other \\
\hline All & 5 & 1 & 4 & 5 & 9 & 73 & 3 \\
\hline Demarcation & 9 & 3 & 7 & 8 & 9 & 61 & 3 \\
\hline No demarcation & 0.5 & 0 & 0.25 & 1 & 10 & 86 & 3 \\
\hline
\end{tabular}


prompting $95 \%$ to treat surgically. Surprisingly, $3 \%$ still opted to discharge such patients, with the likelihood being higher if a demarcation line was present (Figure 5, Table 5).

\section{Scenario 6: superior U-tear retinal detachment 1}

Opinion was split between barricade laser and surgery. This probably represented the limited amount of subretinal fluid present around the tear. Up to $8 \%$ still opted to discharge, with the chances of that being higher with the presence of a demarcation line (Figure 6,

Table 6).

\section{Scenario 7: inferior U-tear retinal detachment}

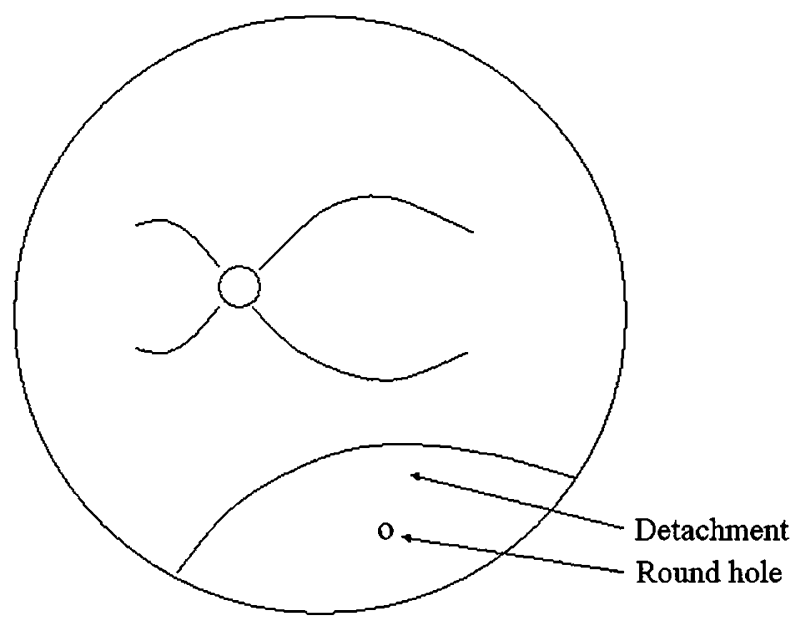

Almost all surgeons opted for surgery in the absence of signs of chronicity. With a demarcation line, $10 \%$ would

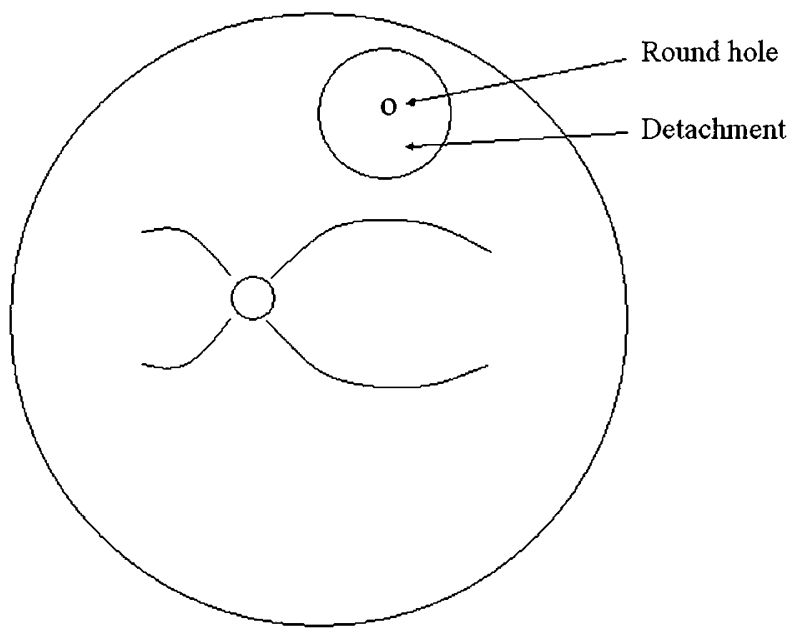

Figure 4 Inferior round hole retinal detachment 1.

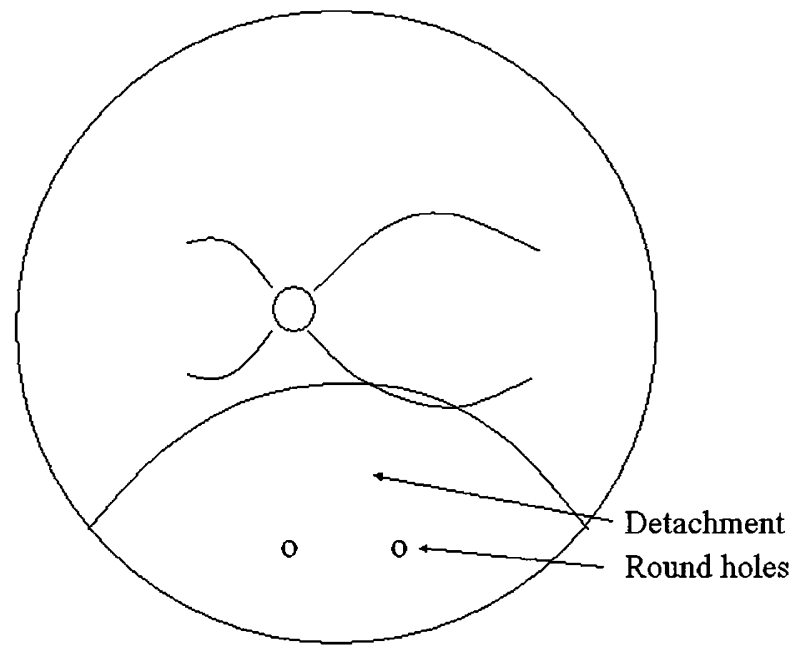

Figure 5 Inferior round hole retinal detachment 2.

Figure 3 Superior round hole retinal detachment.

Table 3 Superior round hole retinal detachment

\begin{tabular}{lccccccc}
\hline$\%$ & Discharge & Observe indefinite & Observe 2 months & Observe 6 months & Laser & Surgery & Other \\
\hline All & 18 & 2 & 5 & 7 & 44 & 18 & 6 \\
Demarcation & 29 & 3 & 9 & 10 & 29 & 15 & 5 \\
No demarcation & 7 & 0 & 2 & 3 & 60 & 21 & 7 \\
\hline
\end{tabular}

Table 4 Inferior round hole retinal detachment 1

\begin{tabular}{lccccccc}
\hline$\%$ & Discharge & Observe indefinite & Observe 2 months & Observe 6 months & Laser & Surgery & Other \\
\hline All & 5 & 3.5 & 7 & 5 & 12 & 64 & 3 \\
Demarcation & 8 & 7 & 10 & 8 & 12 & 51 & 4 \\
No demarcation & 3 & 0 & 3 & 2 & 12 & 78 & 2 \\
\hline
\end{tabular}


consider discharging, while treating with laser was the least popular option (Figure 7, Table 7).

\section{Scenario 8: superior U-tear retinal detachment 2}

No demarcation line meant that all surgeons would treat such a detachment with surgery. With a demarcation line, $6 \%$ opted to discharge, although a high proportion still opted for surgery as a preferred method of treatment (Figure 8, Table 8).

\section{Effect of age}

The effect of age was judged in two different categories. For dialysis and round hole detachments, each scenario was presented at age 15, 30, and 50 years of age, as these types of detachment are more likely to be encountered in this age group. For U-tear detachments, the equivalent ages were 30,50 , and 80 years. Table 9 summarizes the maximum effect a change in age (i.e. from 15 to 50 years for round holes and dialyses and from 30 to 80 years for
U-tear detachments) had on the treatment option chosen. The tendency for surgical intervention reduced with advancing age (Table 9).

\section{Effect of myopia}

In the absence of a demarcation line, there was very little effect on the treatment option chosen. The effect noted when comparing no myopia with $>6 \mathrm{D}$ myopia, with a demarcation line bordering the detachment, is shown in Table 10. Perhaps surprisingly, increasing myopia generally had a very small tendency to increase active intervention (Table 10).

\section{Discussion}

Asymptomatic retinal detachments are most frequently picked up as an incidental finding by the optician, or occasionally when patients present to the eye clinic for an unrelated problem. For the purposes of our study, we did not include asymptomatic detachments in the fellow eye of symptomatic retinal detachments.

Table 5 Inferior round hole retinal detachment 2

\begin{tabular}{lccccccc}
\hline$\%$ & Discharge & Observe Indefinite & Observe 2 months & Observe 6 months & Laser & Surgery & Other \\
\hline All & 3 & 5 & 2 & 1 & 3 & 85 & 1 \\
Demarcation & 6 & 7 & 5 & 2 & 3 & 75 & 2 \\
No demarcation & 1 & 2 & 0 & 0 & 2 & 95 & 0.5 \\
\hline
\end{tabular}

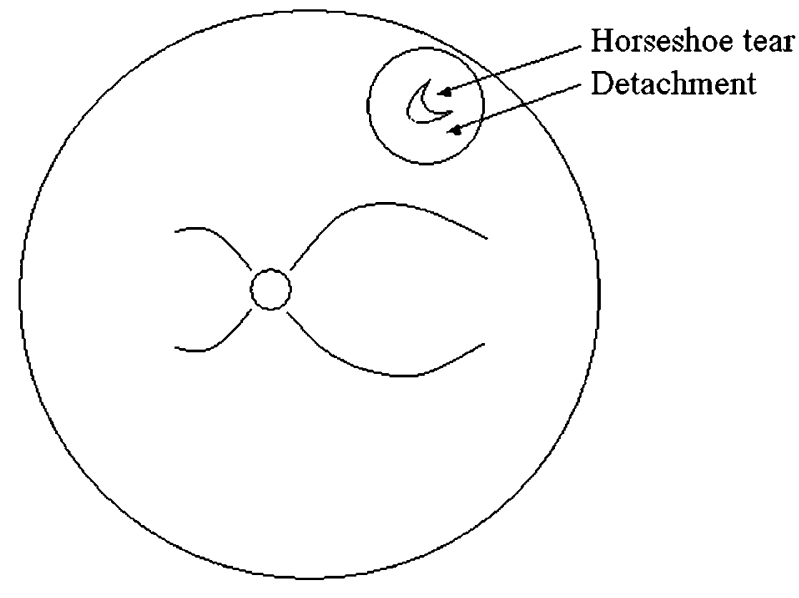

Figure 6 Superior U-tear retinal detachment 1.

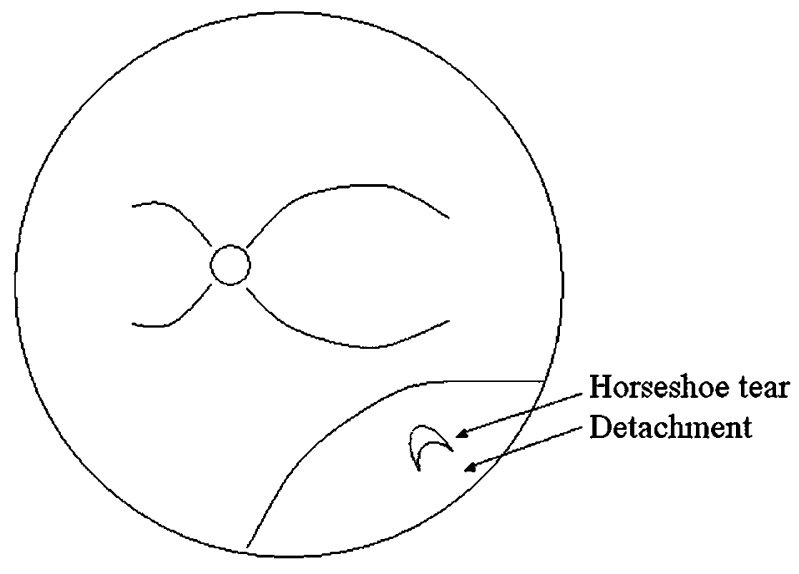

Figure 7 Inferior U-tear retinal detachment.

Table 6 Superior U-tear retinal detachment 1

\begin{tabular}{lccccccc}
\hline$\%$ & Discharge & Observe indefinite & Observe 2 months & Observe 6 months & Laser & Surgery & Other \\
\hline All & 8 & 1 & 1 & 5 & 39 & 43 & 3 \\
Demarcation & 15 & 2 & 2 & 10 & 34 & 35 & 2 \\
No demarcation & 2 & 0 & 0 & 0 & 44 & 51 & 4 \\
\hline
\end{tabular}


The necessity to treat asymptomatic retinal detachments is poorly defined. It is well known that these detachments can progress to become symptomatic, and quite frequently symptomatic detachments have signs of previous chronicity. ${ }^{1}$ It is also well documented that such retinal detachments can spontaneously regress. ${ }^{2,3}$ The exact risk of progression, however, is not known, because of the lack of good natural history data.

Surgical treatment of retinal detachments has an associated morbidity with a risk of reduced vision postoperatively. Many asymptomatic retinal detachment patients are young with visual acuity of $6 / 5$ or better so that a reduction of vision to say $6 / 9$ following surgery is a significant reduction in detail vision. Greven et $a l^{4}$ in a retrospective review of 28 scleral buckling procedures for asymptomatic retinal detachment reported $82 \%$ of eyes to have a final vision within one line of the preoperative

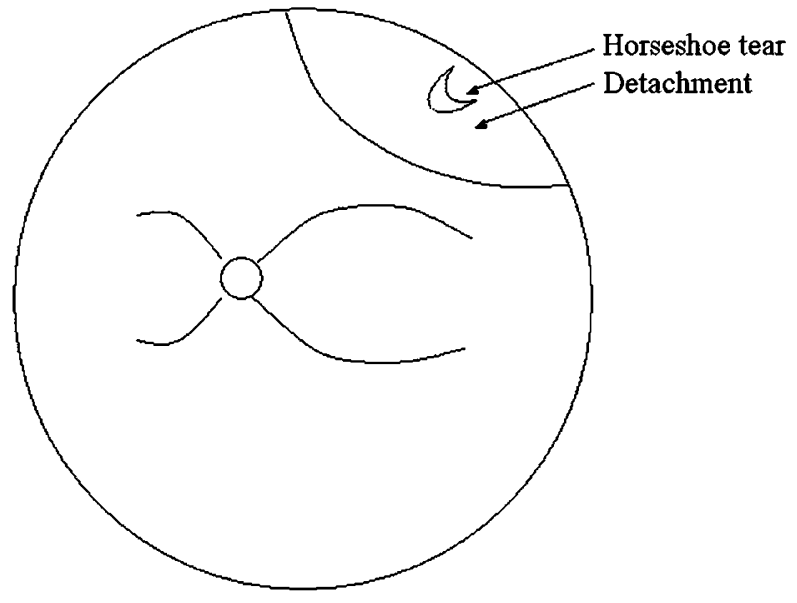

Figure 8 Superior U-tear retinal detachment 2.

Table 7 Inferior U-tear retinal detachment

\begin{tabular}{lccccccc}
\hline$\%$ & Discharge & Observe indefinite & Observe 2 months & Observe 6 months & Laser & Surgery & Other \\
\hline All & 5 & 1 & 4 & 3 & 4 & 81 & 1 \\
Demarcation & 10 & 2 & 7 & 6 & 7 & 66 & 2 \\
No demarcation & 0.5 & 0 & 0.5 & 0.5 & 2 & 96 & 0.5 \\
\hline
\end{tabular}

Table 8 Superior U-tear retinal detachment 2

\begin{tabular}{lccccccc}
\hline$\%$ & Discharge & Observe indefinite & Observe 2 months & Observe 6 months & Laser & Surgery & Other \\
\hline All & 3 & 1 & 2 & 2 & 3 & 88 & 0 \\
Demarcation & 6 & 2 & 5 & 3 & 6 & 77 & 0 \\
No demarcation & 0 & 0 & 0 & 0 & 0 & 100 & 0 \\
\hline
\end{tabular}

Table 9 Effect of age on management chosen

\begin{tabular}{|c|c|c|c|c|c|c|c|}
\hline$\%$ Change & $\begin{array}{l}\text { Inferior } \\
\text { dialysis }\end{array}$ & $\begin{array}{c}\text { Superior } \\
\text { round hole } R D\end{array}$ & $\begin{array}{c}\text { Inferior } \\
\text { round hole } R D 1\end{array}$ & $\begin{array}{c}\text { Inferior } \\
\text { round hole RD } 2\end{array}$ & $\begin{array}{l}\text { Superior } \\
\text { U-tear } 1\end{array}$ & $\begin{array}{l}\text { Inferior } \\
\text { U-tear }\end{array}$ & $\begin{array}{l}\text { Superior } \\
\text { U-tear } 2\end{array}$ \\
\hline Demarcation line & $17 \downarrow S x$ & $7 \uparrow$ Dis & $20 \downarrow S x$ & $10 \downarrow S x$ & $11 \uparrow$ Dis & $23 \downarrow S x$ & $15 \downarrow S x$ \\
\hline No demarcation line & $11 \downarrow S x$ & 0 & $12 \downarrow S x$ & $6 \downarrow S x$ & $\begin{array}{c}3 \downarrow \text { Sx } \\
3 \uparrow \text { Las }\end{array}$ & $7 \downarrow S x$ & 0 \\
\hline
\end{tabular}

Sx, Surgery; Dis, Discharge; Las, Laser.

Arrow shows whether there was a percentage increase or decrease with advancing age.

Table 10 Effect of myopia on management chosen

\begin{tabular}{lcccccrc}
\hline$\%$ Change & $\begin{array}{c}\text { Inferior } \\
\text { dialysis }\end{array}$ & $\begin{array}{c}\text { Superior round } \\
\text { hole } R D\end{array}$ & $\begin{array}{c}\text { Inferior round } \\
\text { hole } R D 1\end{array}$ & $\begin{array}{c}\text { Inferior round } \\
\text { hole } R D 2\end{array}$ & $\begin{array}{c}\text { Superior } \\
\text { U-tear } 1\end{array}$ & $\begin{array}{c}\text { Inferior } \\
U \text {-tear }\end{array}$ & $\begin{array}{c}\text { Superior } \\
U \text {-tear } 2\end{array}$ \\
\hline Demarcation line & $1.5 \downarrow$ Dis & $5 \uparrow$ Las & $1.5 \uparrow$ Las & $1.5 \uparrow \mathrm{Sx}$ & $6 \uparrow \mathrm{Sx} / \mathrm{Las}$ & $3 \downarrow$ Dis & $3 \downarrow$ Dis \\
To Las $\uparrow$
\end{tabular}

Sx, Surgery; Dis, Discharge; Las, Laser.

Arrow shows whether there was a percentage increase or decrease with advancing myopia. 
vision, although the authors do not specify how any of these eyes lost vision. One eye in this study lost two lines of vision following surgery.

Jarret ${ }^{1}$ in his study presented 15 cases of asymptomatic rhegmatogenous retinal detachment; however, 10 of these were fellow eyes with symptomatic pathology in the other eye (eight with retinal detachment). Seven required surgery for progression of detachment between 1 month and 8 years of follow-up. All five superior retinal detachments and two out of 10 inferior detachments came to surgery. Three of the six detachments with a demarcation line required surgery. In the discussion at the end of this paper, Dr Michels comments that we see cases of symptomatic retinal detachment with features of chronicity more often than cases of peripheral nonprogressive or regressed retinal detachment. He recommends surgery in nearly all such cases. In the same discussion, Gass comments that he has found laser or cryotherapy to wall off an asymptomatic detachment in a fellow eye just as effective as scleral buckling, where the detachment does not extend into the central macular area. A noncomparative study by Vrabec and Baumal ${ }^{5}$ seems to confirm Gass's opinion. They showed that 33 of 34 eyes (14 of which were symptomatic), treated with barricade laser alone remained stable, with three of these flattening spontaneously over an average follow-up of 16 months.

With respect to demarcation lines, Benson et $a l^{6}$ presented a retrospective review of 66 cases of retinal detachments with demarcation lines. Twenty of these were asymptomatic patients, nine of which had extended beyond an old demarcation line, essentially showing that their presence does not necessarily mean that the detachment will remain stable indefinitely.

To date, only a few studies have looked exclusively at the natural history of asymptomatic retinal detachments. In 1989, Byer ${ }^{7}$ reported progression in two of 10 cases of subclinical retinal detachments owing to atrophic holes in phakic, nonfellow eyes as part of his follow-up data on patients with lattice degeneration. Follow-up ranged from 8 months to 23 years. Byer recommends observation for such eyes. A recent publication from the same author ${ }^{2}$ showed $11 \%$ of 18 eyes progressed to clinical retinal detachment and an equal number regressed over a follow-up period ranging from 8 months to $>33$ years. He estimated the rate of progression to be $0.8 \%$ per year.

More recently, Cohen ${ }^{8}$ in a prospective study of 18 asymptomatic retinal detachments reported no cases of progression to clinical retinal detachment with follow-up from 1 to over 6 years. One case showed progression over the initial 4 months of follow-up but then remained stable for 4 years. All detachments in this study were predominantly located temporally and inferiorly.
Brod et $a l^{9}$ published a retrospective review of 31 eyes of 28 patients with asymptomatic retinal detachments resulting from tractional tears (six eyes or 19\%) and atrophic holes (25 eyes or 81\%). Follow-up was for 0.5-12 years without intervention. Only two eyes progressed and both were phakic and fellow eyes. The first case was an inferior round hole retinal detachment with a demarcation line and the second developed a new detachment owing to an acute posterior vitreous detachment with new U-tear. The authors recommended observation in reliable patients.

The current survey of retinal surgeons on management of asymptomatic retinal detachments shows that a difference in opinion does exist. There was considerable degree of agreement on best management option for many scenarios, with surgical intervention being most popular in all except scenario 3-a small superior round hole retinal detachment, where laser was most popular. The presence of more fluid, absence of a demarcation line, U-tear detachments, and superiorly located detachments made surgery a more likely choice.

The presence of a demarcation line at the edge of the detachment had a significant effect on management choice, despite the fact that no evidence exists to show that the presence of a demarcation line means that a detachment is less likely to progress and the literature and our own experience show us that many do progress. ${ }^{1,2}$ The presence of an old demarcation line within the detachment indicating progression beyond a previously localized area increased the number inclined to undertake surgery. Myopia had little effect, except when a demarcation line was present and more were likely to treat with laser or surgery. Increasing age of the patient reduced the likelihood of surgical intervention as expected.

Our survey did not include mention of family history because it was felt this would make the survey too time consuming, reducing the response rate. Furthermore, patient involvement in decision-making may also alter the treatment for a given scenario, and this factor could not be included in this survey. It does, however, reflect the differing opinions held about best management of these cases, and the difficulty the patients and doctors have in making the right choice in the absence of evidence in terms of the disease's natural history over the patients' expected lifetime.

In the authors' experience, the majority of patients when presented with the known facts and the undetermined risk of progression opt for treatment of their detachment. One suspects that this is because the patient does not want to live with the worry of progression of the detachment at an unpredictable time in the future. 
We concur with the comments of Michels and Gass, that for the majority of these detachments, many of which are seen in the younger age groups with round holes, progression at a later date in the patient's lifetime is likely. Also, good laser demarcation of the lessextensive, well-defined detachments that do not extend towards the arcades is a reasonable choice and has less potential morbidity than surgery. ${ }^{10}$ However, the difference in opinion shown in this survey suggests that further research is needed in this particular area before any firm treatment guidelines can be formulated.

\section{References}

1 Jarrett WH. Retinal detachment: is reparative surgery always mandatory? Trans Am Ophthalmol Soc 1988; 86: 307-320.

2 Byer NE. Subclinical retinal detachment resulting from asymptomatic retinal breaks. Ophthalmology 2001; 108(8): 1499-1503 (discussion 1503-1504).
3 Byer NE. Spontaneous regression and disappearance of subclinical rhegmatogenous retinal detachment. Am J Ophthalmol 2001; 131(2): 269-270.

4 Greven CM, Wall AB, Slusher MM. Anatomic and visual results in asymptomatic clinical rhegmatogenous retinal detachment repaired by scleral buckling. Am J Ophthalmol 1999; 128(5): 618-620.

5 Vrabec TR, Baumal CR. Demarcation laser photocoagulation of selected macula-sparing rhegmatogenous retinal detachments. Ophthalmology 2000; 107(6): 1063-1067.

6 Benson WE, Nantawan P, Morse PH. Characteristics and prognosis of retinal detachments with demarcation lines. Am J Ophthalmol 1977; 84(5): 641-644.

7 Byer NE. Long-term natural history of lattice degeneration of the retina. Ophthalmology 1989; 96(9): 1396-1401 (discussion 1401-1402).

8 Cohen SM. Natural history of asymptomatic clinical retinal detachments. Am J Ophthalmol 2005; 139(5): 777-779.

9 Brod RD, Flynn Jr HW, Lightman DA. Asymptomatic rhegmatogenous retinal detachments. Arch Ophthalmol 1995; 113(8): 1030-1032.

10 Greenberg PB, Baumal CR. Laser therapy for rhegmatogenous retinal detachment. Curr Opin Ophthalmol 2001; 12(3): 171-174. 